\title{
Conceptual Mapping Importance in EFL learning of Arabic Speaking University Students
}

\author{
Seham Elashhab \\ English Language Center \\ University of Umm Al-Qura \\ Makkah \\ Kingdom of Saudi Arabia
}

\begin{abstract}
The purpose of this paper is to investigate the construct of concept maps as well as the relationship between conceptual maps and foreign language (FL) Arabic speaking learners. It also aims at connecting the previous research to the classroom implementation and FL students' benefits when using this tool to improve their language learning. The researcher demonstrates some examples of conceptual maps from first year students at Umm Al-Qura University in Saudi Arabia. Furthermore, this paper presents an overview of the main trends of thought that have led to the interest in concept mapping as an instructional and learning tool to facilitate the development of Arabic speaking learners' reading, critical thinking, understanding, and remembering the new language words, ideas and facts.
\end{abstract}

Keywords: Concept Mapping, Foreign Language, Learning, Writing, Reading, University Learners.

\section{1- What is concept mapping?}

The idea of concept mapping was originally derived from cognitive theory which sprang out of Ausubel's assimilation theory (Novak and Cañas, 2008). According to Dursteler (2004), the origin of conceptual maps lies in the theories about the psychology of learning of Ausuble who advocated that an individual's subject-matter knowledge is mentally represented in a hierarchy of concepts. Concept maps are part of a family of tools known as graphic organizers, which demonstrate relationships among key ideas that are understood from a learning task (Passmore, 2004). Based on this, Tergan (2005) defines a concept map as a special array that represents elements of knowledge by means of nodes and directly labeled linkages. Together, nodes and labeled links define propositions or assertions about a topic. These propositions can be called semantic units or idea units. In addition, since concept maps provide a flexible format for graphic representation of concepts and the relations among them, they can be defined as graphic representations of different kinds of thinking processes (Osman-Jouchoux, 1997). Further, according to Cimolino, Kay and Miller (2003) Concept mapping is a technique for externalizing a conceptualization in terms of a visual two-dimensional layout, which shows the propositions, believed by the learner as well as other similarity and hierarchy relationships.

Furthermore, Dursteler (2004) assumes that Conceptual maps are simple and practical knowledge representation tools that allow conveying complex conceptual messages in a clear and understandable way. They are represented naturally as graphs. Conceptual maps are structured in a hierarchical way, where the most general concepts lie in the root of the tree and as we descend the structure, we find the more specific ones. Conceptual maps represent relations between concepts in the form of propositions. Concepts are included within boxes or circles whereas the relations between them are explicated by means of lines connecting their respective boxes. The lines have associated words describing the nature of the relation that links the concepts (Dursteler, 2004). Moreover, Taricani (2000) points out that, conceptual maps became external representations that present internal processes of information in structured graphs. Concept maps are also representation of the applications of the dimensions of conceptual processes at different content levels. The nodes and links represent the relationships between the concepts and demonstrate the depth of processing knowledge. Precisely, concepts do not exist in isolation. Each concept depends on one or more relationships to others. A concept map depicts both the hierarchy and relationships among concepts. It demands clarity of meaning and integration of important details. The process of constructing a concept map requires one to think in multiple directions and to switch back and forth between different levels. In attempting to identify the key and associated concepts of a particular topic or sub-topic, one will usually acquire a deeper understanding of the topic and clarification of any prior misconceptions. To the user of a concept map, this ability to switch between different levels and between different concepts or ideas represents an important advantage over more traditional "flat" mechanisms of presenting information. FL learner is made aware of both the complexity and the detail, and it is less easy to "forget" about important aspects of a particular issue (Hentihu, 2013). 
Dansereau (2005) classifies conceptual maps into three types. First, Information maps which are complete node-link maps. An expert to communicate about a topic usually produces them. These maps can substitute for other presentation formats, which are usually provided to learners as learning aids. Second, Guide maps are "fill-in-the-blank" graphic tools that can be used to promote learning. An expert or a teacher provides the structure of the map and the questions within the nodes, and the learners in this type of maps insert the answers. Third, Freestyle maps that are produced by learners to transform material presented in verbal format or to express personal knowledge. This type of mapping is a form of knowledge visualization. These three types of mapping are important for demonstrating relationships between ideas, actions or objects (Dansereau, 2005).

\section{2- Conceptual maps for language learning}

Aconceptual map is a tool for learning new things like vocabulary words and expressions. In fact, conceptual maps are so practical; they are used often in English as a foreign language (EFL) classes to organize ideas. Conceptual maps essentially work in a similar way that our brains do as we remember things better when they are in groups of related things.

According to Chang, Sung and Chen (2002) a limited amount of research has been conducted on its application to the learning of linguistic content. However, there is some evidence that concept mapping is a useful strategy for ESL (English as a second language) students (Block, 1986; Carrell, Pharis, \&Liberto, 1989; Kamhi-Stein, 1993; Knight, Padron, \& Waxman, 1985; El-Koumy, 1999). Conceptual maps facilitate both learning and teaching. They are useful tools that help students learn about how they structure knowledge while supporting the process of knowledge construction or "metaknowledge". In other words, concept maps help students learn how to learn "metalearning". Taricani (2000) assumes that concept maps have been used successfully to promote learning. Meaningful learning occurs when students attempt to integrate new knowledge with existing knowledge. Contrastively, rote learning occurs when students simply memorize information with no attempt to relate it to their prior knowledge. Therefore, Taricani (2000) argues that the rote learner will have a less extensive network than the meaningful learner and less retrieval paths between knowledge concepts. Thus, concept maps are one way to foster and measure meaningful learning in the classroom. Concept maps foster meaningful learning by teaching the connections among course concepts. According to Meaningful Learning Theory, learners build meaning every time they establish substantive rather than arbitrary relations between the study materials and the existing knowledge. Thus, as a student-learning tool, concept maps improve meaningful learning by encouraging students to generate their own connections between concepts. The more meaningful connections a student can show in the map, the better s/he will understand the material. Hence, the process of mapping a map is dependent on prior knowledge, context and constructed understanding (Taricani, 2000).

Dansereau (2005) found that freestyle mapping enhanced college students' educational achievements. Trained college students who used mapping as a note-taking technique in studying text material performed significantly higher in delayed free recall tests than those who used typical study approaches for studying the same text material. Furthermore, Dansereau (2005) noticed that exposure to freestyle mapping training is sufficient to develop better text learning even when the technique is not explicitly used. Dansereau's (2005) research indicates that students recalled more main ideas from an information map than from a corresponding text, whereas, there was no significant differences on the recall of details. In addition, students with low verbal ability or with less prior knowledge often benefit from information maps. Conceptual mapping tool provides a useful focus for students to organize their thoughts and to present information clearly and attractively. It also facilitated communication between students. Thus, learning can be facilitated when the topic is introduced in the form of a conceptual map as it provides a visual image of the concepts under study in a form, which can be focused on very easily. Concepts can be easily revised when required. During the formulation process the concept map brings together the understanding of the meanings and relationships between a wide ranges of ideas. It therefore makes learning or communicating ideas and new information in a more active process, not a passive one (Hentihu, 2013). In three different investigations of the students' attitudes towards the use of concept mapping as a strategy to improve language learning skills, Chularut and DeBacker (2004), Nobahar, Tabrizi and Shaghaghi (2013), and Sabbaghan and Ansarian (2013) all found that most of the students generally showed satisfaction with using concept mapping in their language learning. They concluded that the use of concept mapping boosted the students' attitudes, motivation, and engagement in EFL learning.

\section{3- Conceptual mapping for reading enhancement}

Concerning reading strategies, Osman-Jouchoux (1997) suggests that conceptual maps allow readers to organize their comprehension of the text including information obtained from the macrostructures of the text. 
The researcher's EFL students (Figure 1) demonstrated this suggestion, where mapping technique provides an opportunity to the researcher's first year university students to foster their learning, it enables them to select important information, discard irrelevant information and make connections between main ideas and supporting details as indicated in one of the EFL learners' conceptual maps (Figure 1).

Figure 1: A concept map as a reading strategy

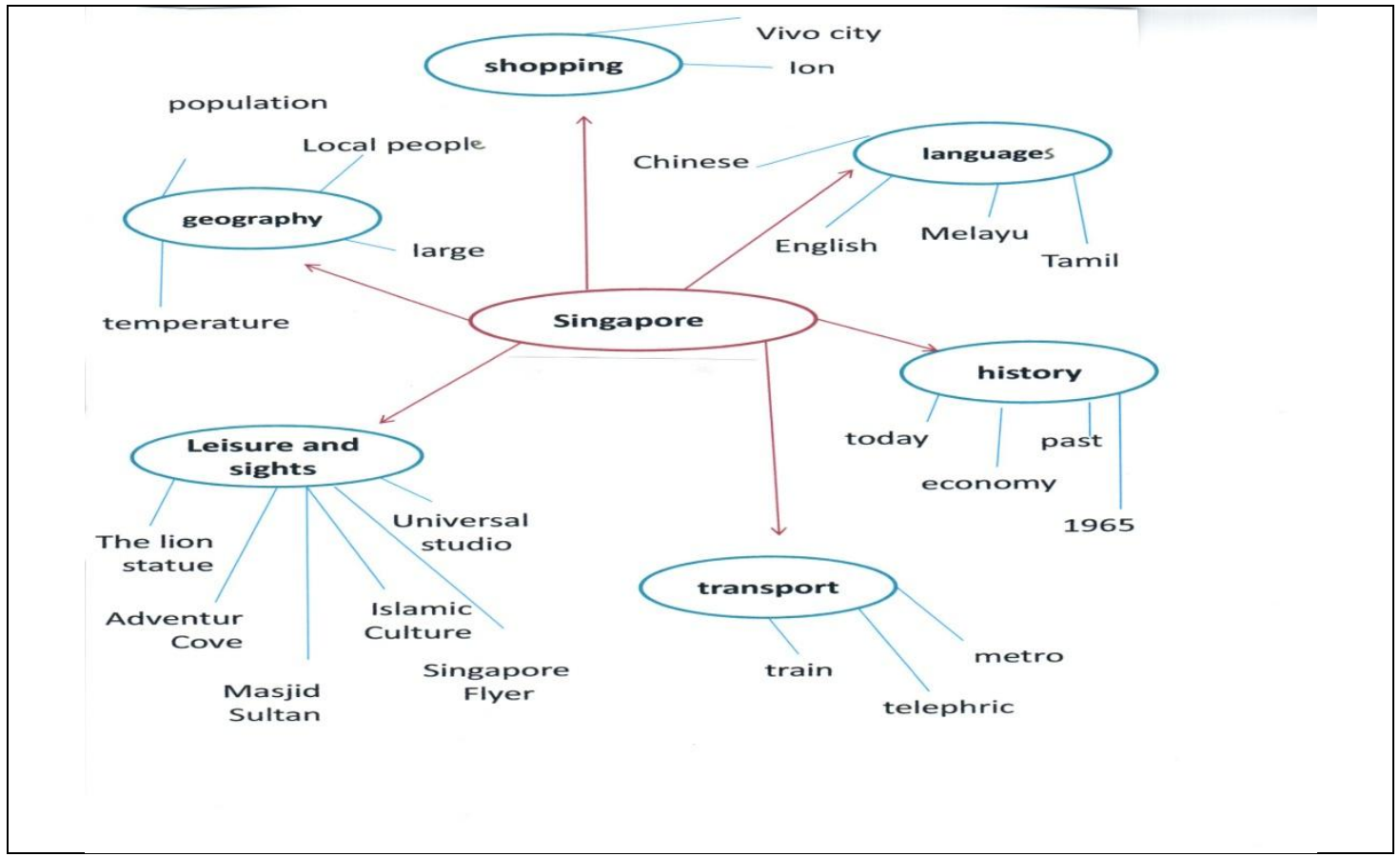

In addition, Chang, Sung and Chen (2002) investigate the effect of concept mapping strategy on text comprehension and summarization. Their subjects were 126 fifth graders from an elementary school in Taiwan. This study involved seven weeks of reading, map construction instruction, and both for the experimental group, as well as pre- and posttests in text comprehension and summarization. Researchers adopted three different concept-mapping methods-map correction, scaffold fading, and map generation - to improve learners' text comprehension. The map-correction group demonstrated more improvement in text comprehension than the map-generation and control groups did. The mapcorrection procedure involved using the concept map to form the content framework of the article being read. Such a framework functions as a structure to demonstrate the content and serves as a reconceptualer of the gist of the text and the linking between ideas.

The findings of this study demonstrate that adopting the strategy of concept mapping training not only improves reading comprehension, but also enhances other linguistic skills related to comprehension such as summarization skills. Graphic organization construction by the readers themselves is effective in promoting autonomous learning and enhancing the depth of learning (Chang, Sung and Chen, 2002). This could be because the process of concept mapping emphasizes the selection of main ideas and key words, connecting and organizing these ideas using relation links, and presenting the major framework of the text. Conceptual maps convert linear textual statements into nonlinear graphic presentations. The tree structure that emerges after the conversion has greater proximity to the macrostructure of the text, making its content easier to retain and retrieve (van Dijk\&Kintsch, 1983). Furthermore, the process of developing a graphic organizer is helpful for continued processing of the concepts themselves and the interrelations among them (Armbruster\& Anderson, 1984). Applications of both graphic organizers and knowledge maps have achieved impressive results in assisting the reader in memorization and comprehension of text content.

In addition to these positive effects of concept mapping strategy on EFL learners' reading ability and its ability to visualize the relationships among concepts, researcher noticed that concept mapping allows the learners to analyse structure, group ideas into categories, get the main ideas of a text easily in order to understand the reading material through concept mapping procedure. This whole process, which requires the learners to find sub-concepts, classify and arrange them, link related sub-concepts, build new cross-links, link old information in one's background knowledge to new information, and give examples to interpret the map, etc., helps them build appropriate monitoring strategy, memorize, and recall their knowledge. This agrees with Tuan \&Thuan's (2011) studies which show that concept mapping not only facilitates reading comprehension in the pre-reading stage but also in the whole reading process. 
Chularut, and DeBacker (2004) investigated the effectiveness of concept mapping as a strategy for learning English among students in English as a Second Language classroom. Specifically, the question addressed in this study was whether the use of concept mapping would improve ESL students' learning from English text. This study compared ESL students in a concept mapping condition to ESL students in an individual study plus discussion condition. Seventy-nine students participated in this study ranged from 15 to 22 years, and included 47 males and 32 females. Survey of Learning Behavior and Achievement Test was used to measure the students' understanding of the five reading passages that were studied during the experiment. These served as pre-tests. At the end of the treatment period, all participants again completed the Achievement Test and the Survey of Learning Behaviors as a post-test. Students in both groups had significantly higher achievement scores at post-test compared to pre-test, but the concept mapping group was found to have significantly greater achievement than the individual study plus discussion group. That is, the opportunity to study the passages individually benefited all students; but, when students were given both an opportunity to study, and a particular strategy to employ during their study time, achievement was enhanced. This provides evidence that concept mapping is an effective tool for learning, because the construction of concept maps may have helped students to build more complex cognitive structures regardimginformation in the passages than they were able to construct based on individual study and in-class discussions (Chularut, and DeBacker, 2004).

In the same vein, Wang and Dwyer (2004) investigated the effects of three concept-mapping strategies in facilitating achievement in different types of educational objectives. The three types of concept mapping strategies were concept identifying, proposition identifying and student generated concept mapping. 105 college level students were assigned to participate in this study. Achievement was measured by three individual criterion tests; one of them was a comprehension test. The material was 2000-word text about the function of the human heart. The findings of this study indicate that concept identifying mapping strategy was effective in facilitating learning the concepts and comprehending the content. By using this strategy students' attention was focused on interacting with the key ideas of the material. This meaningful interaction with the concept maps not only helped the students to remember the main concepts but also to understand other dimensions of the content. As the pre-requisite to construct a meaningful concept map was to identify those main concepts and propositions among them, generating concept maps helped students to interact with the material by identifying the key concepts, the propositions, and the structure of the material. Wang and Dwyer (2004) suggest that the concept mapping strategy aims at difficult areas of learning that have high potentials for enhancement. Hence, concept-mapping strategies should contribute in overcoming those difficulties that students have in processing, organizing and applying the information.

These findings are in agreement with the researcher's notes when her students construct a concept map of a reading text about mulberry tree as they show their interaction with the main ideas and supporting details of the material as shown in Figure 2.

\section{Figure 2: A conceptual map and reading comprehension}

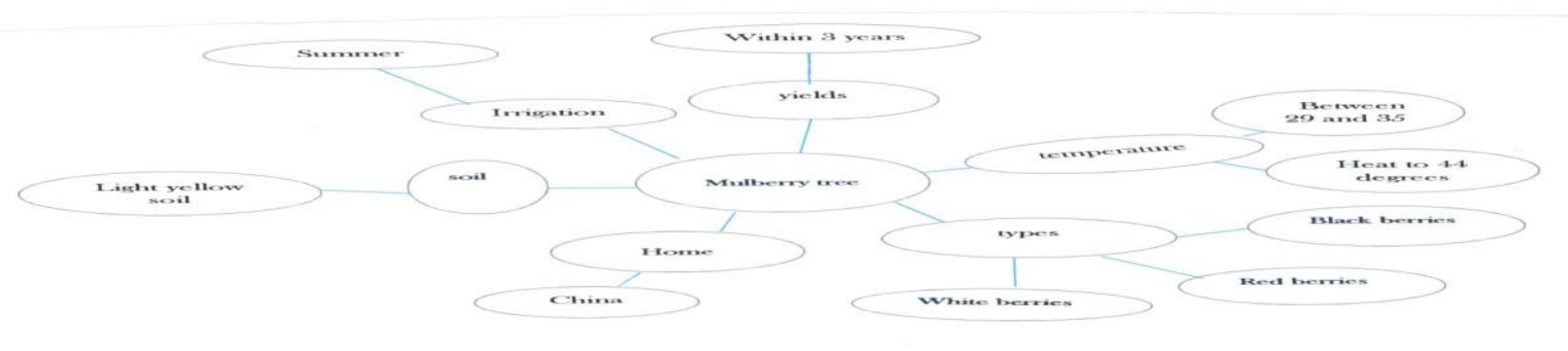


The researcher used concept mapping as a post-reading activity to consolidate textcomprehension.However, conceptual maps can be used as a pre-reading activity, when used as a form of pre-reading activity, concept mapping provided not only the concepts and words that students were about to encounter in the reading text but also offered an overview of the content to be learned. Conceptual mapping as a learning technique contributes in improving the comprehension of the meaning of the new words of a reading text. When EFL students were asked to summarize the reading text in a form of a map, they showed their comprehension of the relationship between the main ideas and the small details by putting this information in different levels on the concept map tree as shown in Figure 2. Ideally the task of concept mapping should be followed by a discussion where the student would have an opportunity to explain the ideas and therefore engage in further meaning-making by working on the subject. Consequently, this would contribute in fostering their text comprehension and vocabulary enrichment.

\section{4- Conceptual maps for writing development}

Implementing concept maps as a step of the writing process helped ESL students to generate and connect concepts in order to be ready for putting them in paragraphs to compose a piece of writing. The researcher considered the whole connected process (a description of associated word clusters and brainstorming activities such as discussions) as a concept mapping strategy in a form of pre-writing activity following Ojima's approach, who used concept mapping as an instructional strategy in a planning phase for writing. Ojima's (2006) study examined the effects of concept mapping as a pre-task activity on three Japanese ESL learners' writing product as well as on their writing process. In this activity, the instructor introduced concept mapping as a pre-writing activity for both in-class and homework compositions. In the procedure of describing concept mapping the instructor first chose the topic, wrote the word on the board then told the students how to create a concept map by choosing a topic first, writing the key word or concept in the centre circle of the map and then expanding their ideas on the topic. Next, she conducted demonstrations of how to develop ideas on the topic by writing the words "fashion" and "be on time" on the board, saying that they are idea subsequences of "watch", drawing lines to connect these words with the topic, and adding more subsequent ideas to the map. The instructor continued by asking the students to discuss in groups for 10 minutes to share their ideas for writing. After that, each student wrote their own compositions in 20 minutes. The results of this investigation revealed that pretask planning activities help the learners to produce better written texts in ESL classes. This research also showed that each learner made distinct applications of the concept mapping strategy in their writing processes due to individual experience, motivation, and task conditions.

Holland et al (2003/2004) found Conceptual Mapping to be a useful technique for helping students plan and structure their essays and projects more effectively. Students were able to improve the structure, coherence and, consequently, the quality of their written work.

In a similar vein, Conceptual mapping helped my low intermediate-beginner level EFL students to organize their vocabulary into levels of ideas. Figure 3 illustrates that a student realized the relationship between concepts. For instance, the student learned that these different types of vehicles (bus, car and metro) are means of transportation concept. She also enriched her vocabulary by using these words in her writing, which may lead to learning the word transportation, as shown in Figure 3 in which Conceptual Mapping can be used to help EFL learners plan and organize their thinking before they start writing or stuck into a project. They can develop all their ideas and see where they relate to each other before deciding the best way to go about things. Thus, Conceptual mappers structure their knowledge by correlating their concepts to each other, in order to help them in realizing the relationship between their concepts and in organizing them in sentences then paragraphs. 
Figure 3: a conceptual map as a pre- writing activity

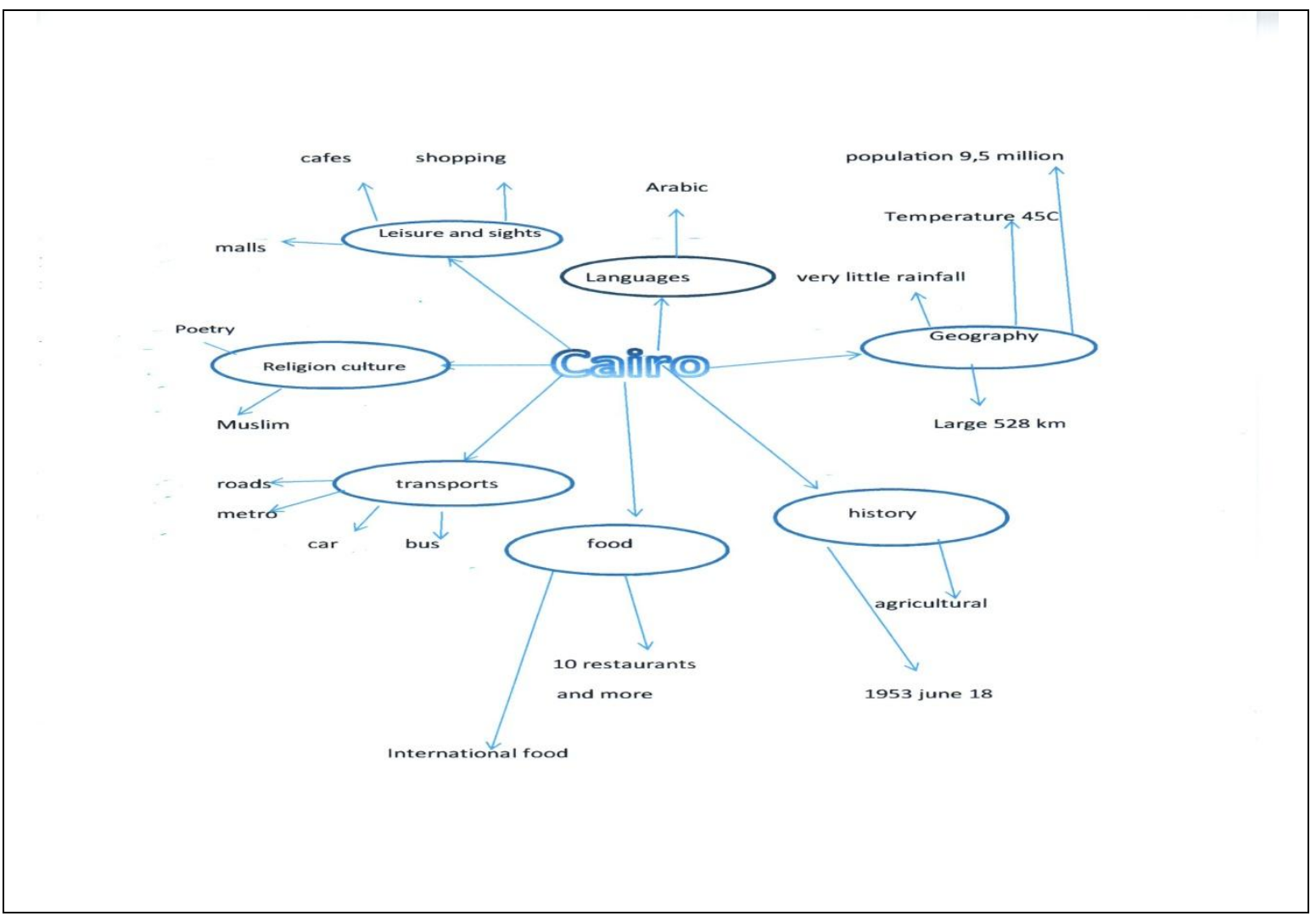

\section{5- Conceptual maps and Reflection}

According to Cimolino, Kay and Miller (2003) Concept mapping is an established technique for supporting learning on several levels. It enables the learner to externalize their understanding of a topic. This serves as a useful means of communication with the teacher and with other learners. At one level, the map itself could be viewed as a form of learner model. This makes concept mapping a natural and appealing approach for supporting learning via reflection on the learner's model. Although that externalization is crucially important for reflection, it is important to emphasize the inherently reflective nature of the completeconcept-mapping task. Cimolino, Kay and Miller (2003) note that students find concept mapping challenging because it requires them to reflect carefully on their understanding of the important concepts and their inter relations.

According to Novak (1998), Hay (2007) and others, concept maps have the value of 'making learning visible as the teacher can actually "see" what ideas the student has about a particular topic and can evaluate students' learning and acquisition of crucial concepts. Furthermore, learning can be aided by knowledge visualization through concept mapping implication (Dansereau, 2005; Cimolino, Kay and Miller, 2003). For instance, learners create or fill out maps to reflect their comprehension of the learned material. Notably, this task would serve both as a basis for the student to verifythat their model was an accurate record of their beliefs and to serve as a basis for reflection (Cimolino, Kay and Miller, 2003). According to Passmore (2004), the linking words that connect the concepts are expressions of the mappers' structural knowledge that reflect their comprehension of the relationships between the concepts. Moreover, the task of conceptual mapping seems to offer an opportunity for the student to get involved with the structured reflection. Whatever the subject of a reflection might be, when sketching a concept map the learner needs to draw on all the concepts that are available to him/her at this particular point of time and makes some connections between the ideas in order to create a map of his/ her current understanding(Jankowska, 2010). This process would allow re-structuring of the map by shifting the concepts around. This proved to be useful and invited further reflection on where particular concepts fitted and how they related to other concepts in my student's vision of their time management as shown in Figure 4 below which is a map created by a first year medical faculty student at the University of Umm Al-Quraa. 
Figure 4: A conceptual map as a reflection strategy

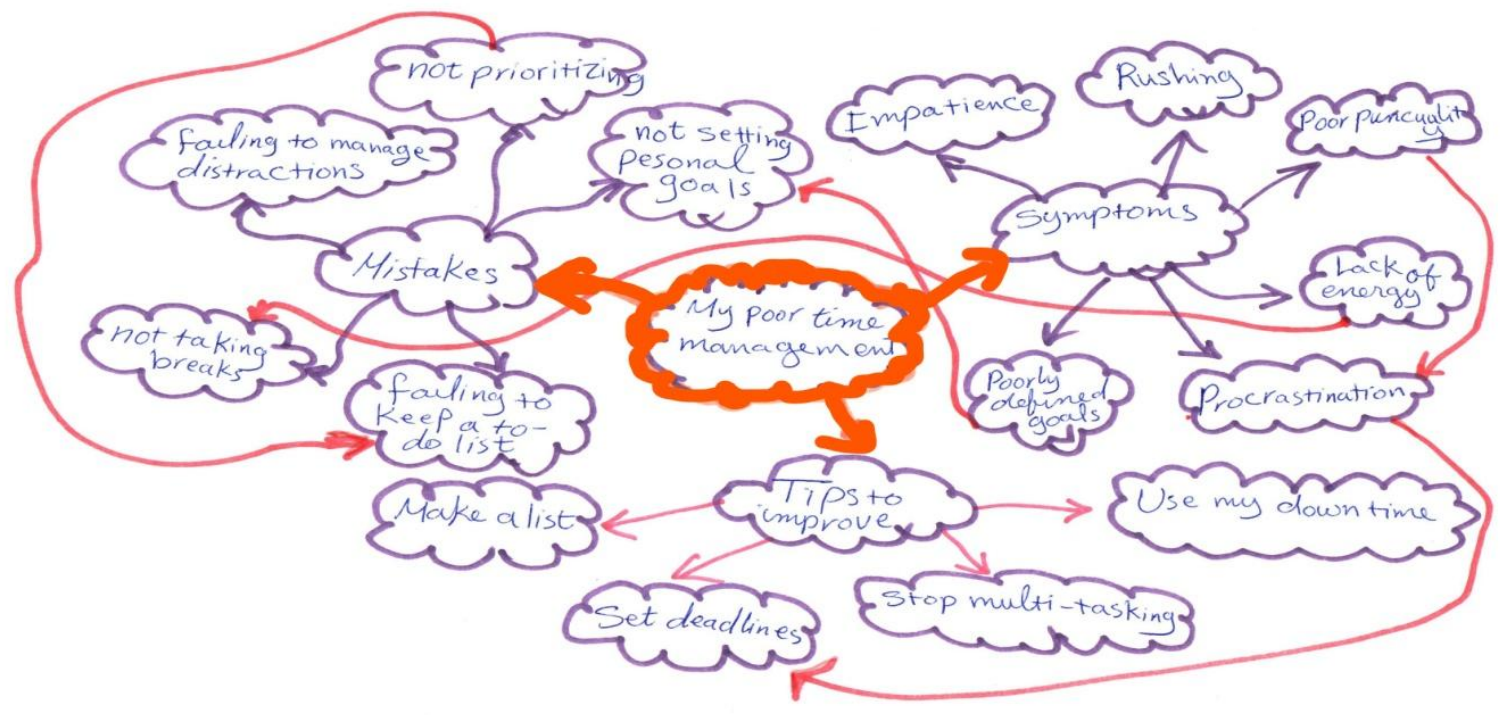

In addition, preferably this task should be followed by a discussion either in a group, with the teacher, or in a written reflective essay, which could help them to realize what needs to be developed, which goals are most important and how to work on them. As far as this study is concerned, concept maps, as graphic representations, had numerous benefits. They reflect learners' thoughts and enable them to see what is in their minds in front of them on their sheets. For instance, the concept map in Figure 4 reflects a learner's problems of time management, mirrors all the related ideas, and visualizes the linkage between problems and their solutions. Furthermore, mind maps helped learners brainstorm and generate new ideas, organize and represent their thoughts to further understand information and discover new relationships, scaffold for cognitive processing, summarize and organize previous learning, maintain collaboration, consolidate educational experiences, develop critical thinking, boost learning achievements and interests (Al-Shaer, 2014).

\section{6- Conclusion}

This paper has explored the main issues relating to concept maps. It has also showed that there are remarkable connections between concept maps and English as a foreign language learning. Concept maps as pedagogical tools, have well established uses to support EFL teaching and learning. As can be seen, the formation of concept maps, whose process is from the prior knowledge to the new concepts, creates meaningful learning. In this process, the students should think in a more complex and critical manner which involves categorizing, inferring, summarizing, comparing and contrasting, evaluating, and reflecting, rather than in a simple linear manner. As a result, learners can understand, retain and recall the subject better when they employ concept maps to represent and organize information (Chularut\&DeBacker, 2004). As a pedagogical tool, the visibility of Conceptual Mapping provides an effective approach for promoting better understanding for EFL Arabic speaking students.

Whenconcept mappingstrategy created correctly and thoroughly, is a powerful way for students to reach high levels of cognitive performance. As students create concept maps, they reiterate ideas using their own words and help identify incorrect ideas and concepts. Students can also add new concepts and links as they see fit. On the other hand, educators are also able to see what students do not understand, providing an accurate, objective way to evaluate areas in which students do not yet grasp concepts fully. Hence, this paper indicates how concept mapping can be integrated into the EFL curriculum to enhance language learning, reading comprehension, writing and reflecting skills. This study recommends EFL teachers incorporate the concept map strategy in their classes as a brainstorming exercise or prewriting activity. EFL students need to be carefully and smartly introduced to the concept mapping strategy, and so a period of direct training is required before students can successfully construct their own concept maps. 
Further, EFL students' first attempt to create a concept map should be done within the context of a simple, familiar topic (e.g., animals or plants). In short, if concept maps are to realize their potential as a teaching/learning tool in writing classes, EFL learners' needs, wants, expectations, and cognitive abilities should be taken into account (AlShaer, 2014)

\section{7- References}

Al-Shaer, I. (2014). Employing Concept Mapping as a Pre-writing Strategy to Help EFLLearners Better Generate Argumentative Compositions. International Journal for theScholarship ofTeaching and Learning, Vol. 8, (2), pp. $1-29$

Armbruster, B. B., \& Anderson, T. H. (1984). Mapping: Representing informative text diagrammatically. In C. D. Holley \& D. F. Dansereau (Eds.), Spatial learning strategies: Techniques, applications, and related issues. New York: Academic Press.

Block, E. (1986). The comprehension strategies of second language readers. TESOL Quarterly, 20, pp. 463-494.

Carrell, P., Pharis, B. G., \&Liberto, J. C. (1989). Metacognitive strategy training for ESL reading. TESOL Quarterly, 23(4), pp. 647-673.

Chang, K., Sung, Y., \& Chen, I. (2002). The effect of concept mapping to enhance text comprehension and summarization. The Journal of Experimental Education, 71, pp. 5-23.

Chularut, P. \& DeBacker, T. K. (2004). The influence of concept mapping on achievement, self-regulation, and selfefficacy in students of English as a second language. Contemporary Educational Psychology. 29(3), pp. 248263.

Cimolino, L., Kay, J., Miller, A. (2003). Incremental student modelling and reflection by verified concept mapping. In Supplementary Proceedings of the AIED2003: Learner Modelling for Reflection Workshop, pp. 219-227.

Dansereau, D. (2005). Node-link mapping principles for Visualizing knowledge and information. In S. O. Tergan\& T. Keller (Eds.), Knowledge and Information Visualization (pp.61-81). Springer: Berlin, Heidelberg.

Dursteler, J. (2004). Conceptual maps. The digital Magazine of InfoVis.net

El-Koumy, A. (1999). Effects of three semantic mapping strategies on EFL students' reading comprehension. (ERIC Document Reproduction Service No. ED 435 193)

Hay, D.B. (2007) Using concept maps to measure deep, surface and non-learning outcomes. Studies in HigherEducation 32(1), 39-57.

Hentihu, I. (2013). Mind Mapping for Second Language Learning. Second Language Acquisition

http://sla-materials.blogspot.com/2013/07/mind-mapping-for-second-language.html

Holland, B., Holland, L., and Davies, J. (2003/2004). An investigation into the concept of Mind Mapping and the use of Mind Mapping software to support and improve student academic performance. Learning and Teaching Projects, pp 89-94

Jankowska, M. (2010). Concept mapping - a reflective tool in personal development planning. ALT Journal, 10, pp.117

Kamhi-Stein, L. (1993). Summarization, note-taking, and mapping techniques: Lessons for L2 reading instruction. (ERIC Document Reproduction Service No. ED 306-816).

Knight, S. L., Padron, Y. N., \& Waxman, H. C. (1985). The cognitive reading strategies of ESL students. TESOL Quarterly, 19, pp. 789-792.

Nobahar, B., Tabrizi A. R. N., \& Shaghaghi, M. (2013). The Effect of Concept Mapping on Iranian Intermediate EFL Learners' Selfefficacy and Expository Writing Accuracy. Theory and Practice in Language Studies, 3(11), pp. 2117-2127.

Novak, J.D. (1998) Learning, creating and using knowledge: concept maps as facilitative toolsin schools and corporations. Mahwah, NJ: Lawrence ErlbaumAssociates.

Novak, J.D \&Cañas, A.J. (2008). The theory underlying concept maps and how to construct and use them. Technical support IHMC Cmap tools 2006-1 Rev01-2008, Florida institute for human and machine cognition. Retrieved from http://www.cmaps.ihmc.us/publications/research.

Ojima, M. (2006). Concept mapping as pre-task planning: A case study of three JapaneseESL writers. Science Direct. System, 34, pp. 566-585.

Osman-Jouchoux, R. (1997). Linking reading and writing: concept mapping as an organizing tactic. ERIC, ED 408955

Passmore, G. (2004). Expanding the power of the concept map. The Alberta Journal of Educational Research, 50, pp. 370-390. 
Sabbaghan, S. \& Ansarian, F. (2013). Do they know that they know? EFL learners' attitude towards concept mapping in listening comprehension. International Journal of Research Studies in Educational Technology. Vol. 2 (1), pp. 57-70.

Taricani, E. (2000). Influences of concept mapping and learning style on learning. Development Papers Presented at the National Convention of the Association for Educational Communications and Technology, 1-2, pp. 208215.

Tergan, S.-O. (2005). Digital concept maps for meaning knowledge and information. In S.O. Tergan\& T. Keller (Eds.), Knowledge and Information Visualization (pp.185-204). Springer: Berlin, Heidelberg.

Tuan, L. \& Thuan, L. (2011). The Linkages between Concept Maps and LanguageLearning. Studies in Literature and Language, Vol. 2, (1), pp. 128-146

Van Dijk, T. A., \& Kintsch, W. (1983). Strategies of discourse comprehension. New York: Academic Press.

Dr. Seham Elashhab has a Ph.D. in Applied Linguistics from University of Ottawa, Canada. She has many years of English teaching experiences. Her research capabilities can be seen in several published papers in Applied Linguistics employing recent theories and approaches in the fields. Her research interests include all aspects of language teaching and learning as well as teacher development and training. She presented her work and conducted workshops in several conferences in various countries. She has been an active member in Accreditation Committee and Recruitment Committee of English Language Centre among others at Umm AlQura University. 